\title{
Summing-up
}

\author{
I J T DAVIES
}

The idea of forming a society to represent the interests of authors of medical books has developed over the last few years and started as a result of the accidental meeting of a number of authors of moderately successful medical books. First comparisons suggested that there was such disparity between some publishers' terms that it was obvious that some authors were at a disadvantage; for example, royalty rates paid by publishers generally seemed to vary between 7.5 and $15 \%$ of the UK retail price of the book. It was also evident that the taxation of royalties and the expenses allowed against royalties before tax was so variable as to suggest almost arbitrary application of the presumed rules. Individual authors' influence over publishers in respect of the format and production of their books varied from complete participation by the author in discussions about production to a complete inability to influence even major decisions such as production of paperback or hardback versions. Authors themselves spanned a whole range-from those who saw little or no fault with their publishers to those who asserted that they would prefer to hide their light rather than return to their previous publisher.

We therefore circulated 3000 medical authors culled from the Medical Directory, and devised a suitable title for our prospective society-hitting on the Society of Medical Authors, which conveniently becomes the acronym SOMA. We had replies from over 1000; the eminence and prestige of some of those who replied were surprising. The literary output of those interested ranged from standard medical texts to obscure poetry, musical scores, and political pamphlets. About 850 of those who replied said that they would be interested in a society for medical authors and felt that there was a need for such a society.

\section{Formation of a society}

From the large number of replies to our questionnaire it was clear that many authors wished to meet to discuss the formation of a society and to discuss questions of taxation, royalty rates, and relations with publishers but, above all, to meet a collection of their fellow authors. A meeting was therefore convened at the Royal Society of Medicine in London on 20 October 1978 to discuss the formation of a Society of Medical Authors. The meeting was attended by over 100 authors and lively discussion

Raigmore Hospital, Inverness IV2 3UJ

I J T DAVIES, FRCPED, MRCP, consultant physician followed each of the papers presented. At the conclusion of the meeting we considered further action-in particular, our possible relationship with the Society of Authors. In general, opinion favoured close liaison with the Society of Authors particularly bearing in mind their skill in handling authors' affairs over the last 90 years. There were, however, certain reservations with regard to how helpful this society could be to medical authors. The Society of Authors is now a registered trade union with a membership fee of $£ 18$ a year, and it was questioned whether a prospective author could join the society or whether he would want to before he had a book published. There might also be difficulties with regard to the authors and editors of multiauthor books. Some of the facilities (such as pension schemes) of the Society of Authors might not be applicable to medical authors. It was suggested that SOMA itself should have some form of collective membership of the Society of Authors.

\section{Not anti-publisher}

One theme which came out of the discussions was that any society of medical authors should not be seen to be "antipublisher," and, indeed, most of the authors who participated were sympathetic to the problems of publishers and most spoke of their experiences of cordial relationships with publishers; nevertheless, there were many examples given in which publishers' terms fell below the average. Evidently no publisher contract is perfect or even average in every respect, and SOMA could have a useful role in identifying those contracts which clearly fell below average and in guiding authors to those publishers offering terms most advantageous for the particular requirements of that author's work. Possibly, too, there might be scope for SOMA itself to enter publishing and promote a closer understanding between authors and publishers.

The meeting decided that a working party should be established to examine the need for and aims of a possible society of medical authors and that the working party would report to a reconvened general meeting in the first months of 1979. The working party will consist of Dr I J T Davies, Dr Peter Abrahams, Dr David C Evered, Dr Stephen Lock, Dr Jacob S Norell, Dr Robert Richardson, Dr Klaus F R Schiller, Dr P N Sperryn, and Dr Joan F Zilva.

Further information about SOMA can be obtained from $\mathrm{Dr}$ Davies at Raigmore Hospital, Inverness.

\begin{abstract}
Have the rhythms (physical 23 days, emotional 28, and intellectual 33) mentioned in a recent article ${ }^{1}$ on biorhythms and the part they can play in accidents any medical substantiation?
\end{abstract}

There are many scientific reports describing rhythmic change in the structure, physiology, and behaviour of plants and animals, including man. In some specialties, notably endocrinology, information about such rhythms is considered essential to the understanding and treatment of disease. Twenty-eight day rhythms in the menstruating woman are well known, and some association between accident-proneness and the premenstrual phase has been shown. Rhythms with frequencies of around 23 and 33 days have occasionally been detected in physiological and psychological studies, and it may be premature to dismiss the "biorhythm" theory even though to most physicians it sounds an improbable hypothesis.
Little has yet been published about the "biorhythms" described in the Drive article. One published study investigated the claim that analysis of biorhythms might allow prediction of the day of death, but could not substantiate the claims made. There is at least one unpublished investigation showing a failure to predict success in a sporting event, and an analysis of 400 mining accidents found no empirical or theoretical support for the biorhythm theory. ${ }^{2}$ There appear to be insufficient statistically validated facts available to justify acceptance of the theory of biorhythms or their applications. The proposal that peaks and troughs of rhythms can be predicted from birth date alone is the mort improbable part of the theory. ${ }^{1}$ Drive, 1978, $\mathrm{p} 40$.
2 Persinger, $\mathrm{A}$, Cooke, W J, and Janes, Jean T, Perception and Motor Skills,
1978, 46, 423, 